Journal of the Electrochemical Society, 1992, Volume 139, Issue 6, Pages 1530-1535.

ISSN: 0013-4651

DOI: $10.1149 / 1.2069450$

http://www.electrochem.org/

http://scitation.aip.org/getpdf/servlet/GetPDFServlet?filetype=pdf\&id=JESOAN000139000006001530000001\&idty pe $=$ cvips\&prog $=$ normal

(C) The Electrochemical Society, Inc. 1992. All rights reserved. Except as provided under U.S. copyright law, this work may not be reproduced, resold, distributed, or modified without the express permission of The Electrochemical Society (ECS). The archival version of this work was published in Journal of the Electrochemical Society, 1992, Volume 139, Issue 6, Pages 1530-1535.

\title{
Corrosion and Passivation of Fe and FeN Films
}

\section{Brusic,* G. S. Frankel,* B. M. Rush, A. G. Schrott, C. Jahnes, M. A. Russak, and T. Petersen}

IBM Research Division, T. J. Watson Research Center, Yorktown Heights, New York.

* Electrochemical Society Active Member.

\begin{abstract}
The role of nitrogen in corrosion and passivation of thin Fe-N films was studied. Sputtered films with different levels of nitrogen were characterized for composition, conductivity, stress, and crystallinity. Corrosion and passivation of the films were evaluated by electrochemical measurements combined with in situ ellipsometry and $e x$ situ $\mathrm{x}$-ray photoelectron spectroscopy. The results indicate that in deaerated solutions the primary action of $\mathrm{N}$ is to reduce the catalytic activity of the surface for the hydrogen reaction and thereby reduce corrosion. In aerated solutions the corrosion rate increases with $\mathrm{N}$ content. Kinetics of the protective oxide formation as a function of potential, percent $\mathrm{N}$, and the presence of borate buffer are discussed in detail. The work is relevant to the behavior of oxide-free Fe-N surfaces in contact with mild, nearly neutral electrolytes, such as could be used in fabrication of magnetic recording heads.
\end{abstract}

The role of nitrogen on corrosion and passivation of $\mathrm{Fe}$ and $\mathrm{Fe}$-alloys is of interest for several reasons. The addition of $\mathrm{N}$, even in amounts of 1 atom percent $(\mathrm{a} / \mathrm{o})$, is very effective in promoting passivation and enhancing pitting resistance in stainless steel, particularly in the presence of Mo $(1,2)$. Also, the addition of $\mathrm{N}$ to thin Fe films results in high saturation magnetization, low coercivity, and uniaxial anisotropy, properties which are suitable for fabrication of high-density magnetic recording heads (3-5). Studies of magnetic materials have focused mainly on the magnetic properties with only a few references to the corrosion resistance. Depending on film preparation, thin Fe films were described as "susceptible to rust" or "rust proof in water (3). Lo et al. (4) evaluated the corrosion rate of $\mathrm{N}$-doped and undoped ion beam sputtered Fe films in deaerated $0.1 \mathrm{~N} \mathrm{Na}_{2} \mathrm{SO}_{4}$ and concluded that only films with more than 5 a/o $\mathrm{N}$ have high corrosion resistance. The mechanism by which nitrogen effects the corrosion of $\mathrm{Fe}$ $\mathrm{N}$ films was not discussed. Several possible explanations for the effect of $\mathrm{N}$ on corrosion (of steels) have been put forth (6-11). However, the final mechanistic picture has yet to be determined.

In this work, the effects of nitrogen on the corrosion and passivation of thin Fe films doped with variable but controlled amounts of nitrogen are studied. The work is primarily relevant to the behavior of oxide-free Fe-N surfaces in contact with mild, nearly neutral electrolytes, such as may be found in fabrication of the thin film magnetic recording heads. 


\section{Sample Preparation and Characterization}

Thin film samples of $\mathrm{Fe}$ with 0 to $21 \mathrm{a} / \mathrm{o} \mathrm{N}$ were prepared by dc magnetron sputtering from a pure $\mathrm{Fe}$ target in $\mathrm{Ar} / \mathrm{N}_{2}$ gas mixtures of preselected ratios, at room temperature with a substrate bias of $-100 \mathrm{eV}$. Corrosion experiments were performed on about $150 \mathrm{~nm}$ thick films of $\mathrm{Fe}$ and $\mathrm{Fe}-\mathrm{N}$ deposited onto glass substrates. The deposition rate was constant for all of the films, except those with more than $20 \mathrm{a} / \mathrm{o} \mathrm{N}$, in which case the rate was somewhat lower, and the films picked up a measurable amount of argon. Film composition (percent N, percent Ar) was determined by Rutherford backscattering (RBS) and x-ray photoelectron spectroscopy (XPS) techniques. Films were also characterized for conductivity (four-point probe), stress (by physical measurement of the curvature radius) and crystallinity [by x-ray and transmission electron microscopy (TEM) analyses].

Corrosion and passivation of the films were evaluated by electrochemical measurements combined with in situ ellipsometry and ex situ XPS. Most of the experiments were conducted in an air-tight KEL-F cell equipped with quartz windows for simultaneous observation by ellipsometry. In most cases the electrolyte used was $0.1 \mathrm{JV} \mathrm{K}_{2} \mathrm{SO}_{4} / \mathrm{KOH}, \mathrm{pH} 7-11$, phosphate buffer and boric acid/borate buffer, $\mathrm{pH} 7$ and 8.2. $\mathrm{N}_{2}$, air, or $\mathrm{O}_{2}$ was bubbled before and during the experiment. In some of the experiments, the electrolyte also contained $10^{-5} \mathrm{M}$ Fe-ethylene diamine sulfate. This amount of Fe-ions was added in order to obtain a fixed value of the reversible potential for Fe dissolution and thereby a more quantitative comparison of the rate of Fe dissolution as a function of $\mathrm{N}$-content. In a few experiments aimed at the stability of the native oxide, acidic electrolytes such as dilute sulfuric acid $(\mathrm{pH} 2)$ were used. The potentiostatic technique was used for reduction of native oxides and for formation and reduction of passive anodic films. Polarization resistance and potentio-dynamic polarization curves were used to determine the corrosion rate and the active-passive behavior. A few of the experiments were conducted in a simple cell designed to measure metallic corrosion in pure water or in electrolytes with a high ohmic resistance (12). All potentials were measured and are referenced with respect to mercurous sulfate electrode (MSE).

\section{Results and Discussion}

As-deposited films.-TEM analysis, performed on $100 \mathrm{~nm}$ thick films, shows that the grain size of the films significantly decreases with an increase in a/o N. The film morphology and crystalline structure are discussed in detail separately (13). A brief summary will be given here. Films prepared with no nitrogen flow were composed of bcc $\alpha$-Fe with an average grain size of $70.5 \mathrm{~nm}$. As the nitrogen content increased, the grain size decreased, reaching an average size of $34.3 \mathrm{~nm}$ in films with 20 a/o $\mathrm{N}$. In the films containing nitrogen, $\mathrm{Fe}_{4} \mathrm{~N}, \mathrm{Fe}_{16} \mathrm{~N}_{2}$, and $\mathrm{FeN}_{2}$ were detected. In all cases, the amount of the Fe-nitrides was small and not quantifiable using selected area x-ray diffraction. However, for films in excess of $10 \%$ nitrogen, more $\mathrm{FeN}_{2}$ was found. Since the nitrides were randomly distributed through the Fe matrix, some amount was likely to be present at the surface, which could influence the corrosion behavior of the iron. As the amount of $\mathrm{N}$ increased there was an increase of resistivity, an increase in native oxide thickness, as determined by ellipsometry, and variation of compressive stress (Table I). The film composition which is listed in the table is the result of the RBS analysis.

The increase in the native oxide thickness with an increase of percent $\mathrm{N}$ was also

confirmed by XPS. The spectra for the Fe $2 p$ line indicated that the intensities of the peak due to 
the $\mathrm{Fe}$ in the oxide $\left(\mathrm{Fe}^{\mathrm{ox}}\right)$ clearly increased as the $\mathrm{N}$-content increased.

Table I. Resistivity, stress, and oxide thickness on Fe-N films.

\begin{tabular}{rccc}
\hline $\begin{array}{c}\mathrm{N} \\
(\mathrm{a} / \mathrm{o})\end{array}$ & $\begin{array}{c}\rho \\
(\mu \Omega-\mathrm{cm})\end{array}$ & $\left(\right.$ dynes $\left./ \mathrm{cm}^{2} \times 10^{-9}\right)$ & $\begin{array}{c}\text { Oxide } \\
\text { thickness } \\
(\mathrm{nm})\end{array}$ \\
\hline 0 & 24 & -8.5 & 2.5 \\
1.5 & 41.7 & -6.06 & 2.6 \\
3 & 61.7 & -9.3 & 2.7 \\
5 & 77.7 & -10 & 2.4 \\
13.1 & 161 & -2.9 & 3.6 \\
20.6 & 183 & -2.8 & 4.2
\end{tabular}

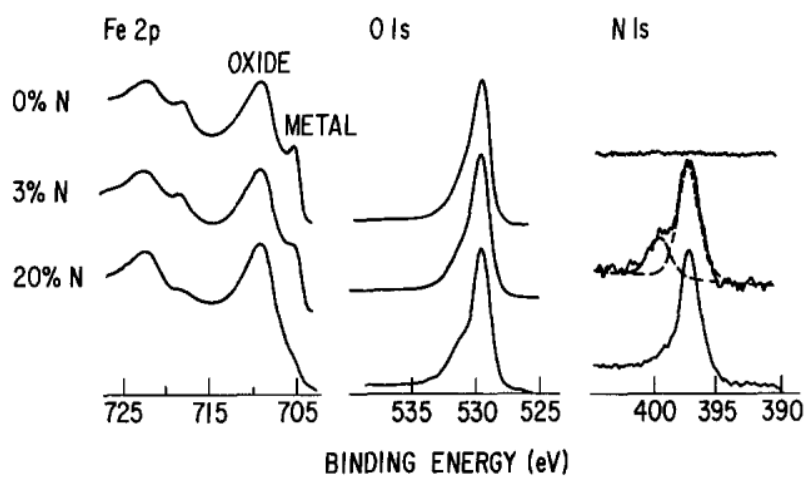

Fig. 1. Binding energies for $\mathrm{Fe} 2 \mathrm{p}$, $\mathrm{N}$ Is, and $\mathrm{O}$ Is spectra on $\mathrm{Fe}-\mathrm{N}$ film covered by native oxide.

Composition of the native oxide.-The photoemission peaks corresponding to the $\mathrm{Fe} 2 \mathrm{p}$, $\mathrm{N}$ 1s, and $\mathrm{O}$ 1s lines are given in Fig. 1 for a native oxide film on Fe with 0, 3, and 20.4 a/o $\mathrm{N}$ (as determined by RBS). The binding energy for the Fe $2 p$ corresponding to the oxide indicated that the oxide is mostly $\mathrm{Fe}_{2} \mathrm{O}_{3}$. The peak in the $\mathrm{Fe} 2 \mathrm{p}$ spectrum at lower binding energy represents nonoxidized Fe. The intensity of photoelectrons of a given energy, generated at a depth $l$, which emerge with an angle $\theta$ with respect to the sample's normal (take off angle), will decay exponentially as $\left\{\mathrm{e}^{-1 \lambda \cos \mathrm{e}} \theta\right\}$, where $\lambda$ is a mean-free path for the electrons in the solid. Therefore the change in the relative intensities of the nonoxidized and oxidized peaks with take off angle allows determination of the vertical distribution of the different species and evaluation of the oxide thickness. In this case, the relative intensity of these peaks indicates that the oxide film thickness is less than the detection depth $=3 \lambda$. $(\leq 50 \AA)$ for the Fe $2 p$ photoelectrons excited with $\mathrm{Al} \mathrm{K}$ a radiation (14).

Closer evaluation of the $\mathrm{N}$ and $\mathrm{O}$ signals (Fig. 1) shows that there are two nitrogen and oxygen species. By comparing spectra taken at different take off angles (normalized to the background) the high binding energy feature of both the $\mathrm{O}$ and $\mathrm{N}$ peaks may be determined to correspond to a species at the surface (Fig. 2). Figure 1 shows that the ratio of these $\mathrm{N}$ and $\mathrm{O}$ surface to bulk features decreases with increasing nominal $\mathrm{N}$-content, and this is due to an increase in the bulk intensities. The $\mathrm{N}$ to $\mathrm{O}$ ratios do not exhibit a significant variation with take 
off angle. Furthermore, the $\mathrm{N}$ to $\mathrm{O}$ peak area ratio seems to be constant for all $\mathrm{N}$ concentrations, and the amount of $\mathrm{N}$ in the oxide deduced from these peak ratios and tabulated sensitivity factors is very small $(=0.5 \mathrm{a} / \mathrm{o})$.

One reasonable explanation is that the surface oxide contains small amounts of oxidized $\mathrm{N}$, small enough not to be detectable by other techniques, e.g., x-ray diffraction measurements. The $\mathrm{N}$ peak in the Fe-matrix and in the oxide matrix has a binding energy of 397.1-397.3 eV and seems to act as oxidation promoter, taking the electrons from the iron. The surface $\mathrm{N}$ in the oxide is different from that of the bulk; it seems to be giving up electrons and oxidizing, since the corresponding XPS peak has a higher binding energy. A deconvolution of the $\mathrm{N}$ peak in Fig. 1

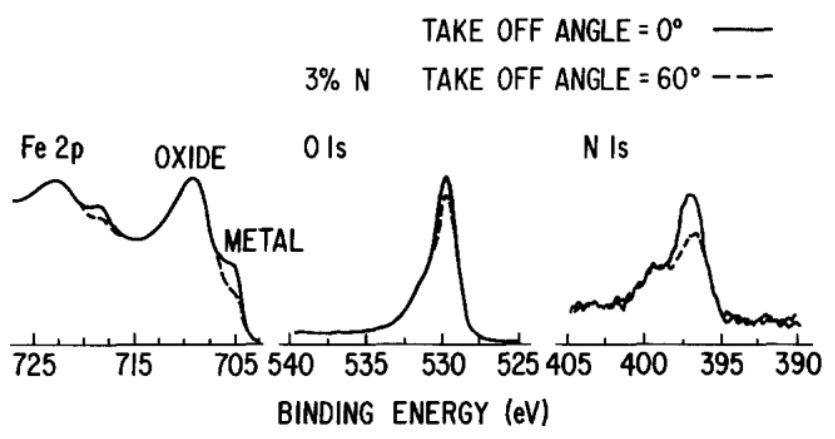

Fig. 2. Angular dependence of $\mathrm{N} 1 \mathrm{~s}$ and $\mathrm{O} 1 \mathrm{~s}$ peaks in photoemission spectra.

indicates that the surface feature is produced by a peak at $=399.7 \mathrm{eV}$. This is consistent with the differences in electronegativity between $\mathrm{N}$ and its neighbors, $\mathrm{Fe}$ in the bulk and $\mathrm{O}$ in the film. The binding energy of the surface $\mathrm{N}$ is close to values reported for $\mathrm{NaNO}_{2}$ and $\mathrm{NH} 4 \mathrm{NO}_{3}(15)$.

As the film composition is mostly Fe-oxide, there should be a nitrogen enrichment at the oxide/metal interface, as observed by others (8). Such an enrichment indeed might occur, but it does not explain the existence of the $\mathrm{N}$ peak at higher binding energy. Due to the exponential attenuation of the XPS signal, most of the $\mathrm{N}$ signal arises from the oxide film and the surface (rather than the bulk of the film which is measured by RBS).

Stability of the native oxide.-In water and neutral, non-aggressive, electrolytes exposed to air, the native oxide on all of the samples is stable (during 30 min needed for measurements). The corrosion measurements on such films indicate that the film with 0 a/o $\mathrm{N}$ has somewhat lower corrosion potential and higher corrosion rate $\left(-0.5 \mathrm{~V}\right.$ and $\left.9 \times 10^{-8} \mathrm{~A} / \mathrm{cm}^{2}\right)$ than films with $\geq$ $1.5 \mathrm{a} / \mathrm{o} \mathrm{N}$, all of which show similar values $\left(-0.38 \mathrm{~V}\right.$ and $\left.2 \times 10^{-8} \mathrm{~A} / \mathrm{cm}^{2}\right)$. Thus, if the surface is not purposely reduced, the corrosion tests in such environments primarily reflect the stability of the native surface oxide and not the properties of the underlying metal.

In acidic environments, however, the native oxide film spontaneously dissolves. The stability of native oxide on Fe-N films is much higher than on Fe alone and increases with $\mathrm{N}$ content. Upon exposure to $\mathrm{pH} 2$ sulfuric acid, the potential drops from a high value indicating passivity to a low value ( -950 to $-1030 \mathrm{mV}$ ) reflecting an active dissolution, in $2.5 \mathrm{~min}$ on $\mathrm{Fe}$; $14.5 \min$ for $1.5 \mathrm{a} / \mathrm{o} \mathrm{N} ; 15.5 \min$ for $3 \mathrm{a} / \mathrm{o} \mathrm{N} ; 15 \min$ for $5 \mathrm{a} / \mathrm{o} \mathrm{N} ; 21.5$ for $13 \mathrm{a} / \mathrm{o} \mathrm{N}$, and more than 37 min on Fe with 20.4 a/o $\mathrm{N}$. The beneficial influence of $\mathrm{N}$ is often attributed to the 
stability of the N-enriched metal matrix $(8,9)$ rather than to nitrogen incorporation into the oxide film (8). In contrast, however, we have observed that, once the oxide is dissolved in acidic media, the dissolution rate of high $\mathrm{N}$-containing films is significantly faster than that of the $\mathrm{N}$ free film. Also, for the first time, $\mathrm{N}$ is detected in the Fe-oxide film. Thus, the lower corrosion susceptibility of Fe-N is likely due to a role of $\mathrm{N}$ in the stability of the oxide, the finer grain size and possibly the kinetics of oxide growth. This will be discussed below.

Corrosion and passivation of oxide-free films in deaerated electrolytes.-Potentiostatic reduction (at $-1.4 \mathrm{~V}$ ) of the native oxide is a relatively fast process, leading to a bare surface in about $3 \mathrm{~min}$. The ellipsometric parameters $\Delta$ and $\psi$ are sensitive functions of the composition of the reduced surface and both decrease with $\mathrm{N}$ content. For example, A changes from $117.18^{\circ}$ for $\mathrm{Fe}$ to $115.86^{\circ}$ and $114.89^{\circ}$ as the $\mathrm{N}$ increases to 1.5 and $3 \mathrm{a} / \mathrm{o}$, respectively, reaching $110.97^{\circ}$ for Fe with 20.4 a/o N. The calculated refractive index of the oxide-free surface decreases with an increase in a/o N, from 3.27-3.89i for Fe to 2.91-3.59i for Fe with 20.4 a/o N. This proportional change in optical properties most likely indicates a decrease of metal film density with an increase in $\mathrm{N}$. At the potential at which the oxide reduction is performed, two other reactions are possible, reduction of $\mathrm{H}^{+}$-ions and reduction of $\mathrm{N}$ into $\mathrm{NH}_{4}+$. The latter reaction, if present, would complicate the interpretation of the data because it could alter not only local $\mathrm{pH}$ but the $\mathrm{N}$ content on the surface. We have no indication, using ellipsometric data as a measure, that such a reaction occurs. Judging from the data obtained on oxide-free surfaces, surface enrichment in $\mathrm{N}$ should cause an easily measurable decrease in ellipsometric parameters, yet the optical properties of the surface are constant with time for the duration of the test, i.e., for at least $10 \mathrm{~min}$ at the low cathodic potential after the reduction of the native oxide and for more than 40 min at such potential after the reduction of anodically formed oxide. However, there is a possibility that the reduction of the iron oxide leads to some surface enrichment of iron, which in view of small variations of oxide thickness should be small and similar for all samples. Thus, the reduced surface is thought to be a good reflection of the matrix with a variable $\mathrm{N}$ content.

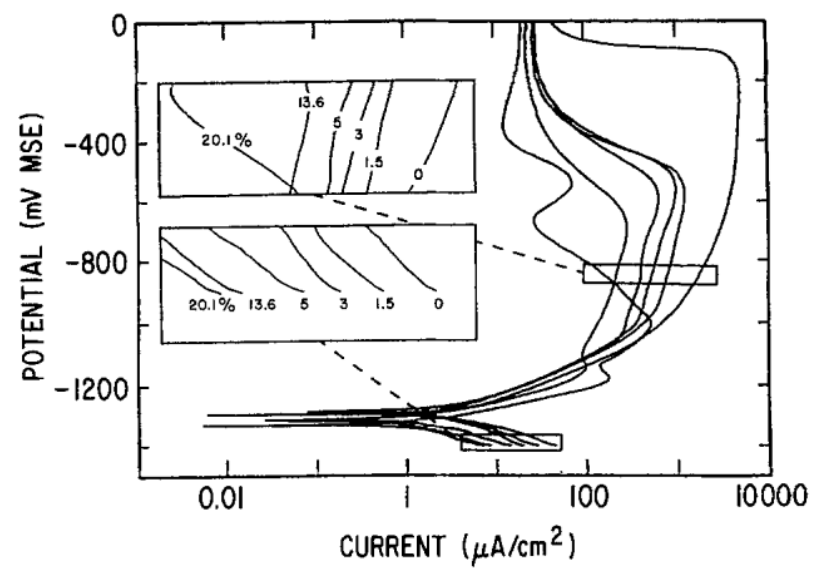

Fig. 3. Potentiodynamic polarization curves obtained on $\mathrm{Fe}-\mathrm{N}$ with 0 to $20.4 \mathrm{a} / \mathrm{o} \mathrm{N}$ in $\mathrm{N}_{2}$-saturated $0.1 \mathrm{~N}$ $\mathrm{K}_{2} \mathrm{SO}_{4}$. Potential was swept with a rate of $5 \mathrm{mV} / \mathrm{s}$. 
Potentiodynamic polarization measurements after cathodic reduction are shown in Fig. 3 and 4 for sulfate and borate solutions, respectively. In both buffered and unbuffered deaerated electrolytes the cathodic current decreases as the nitrogen content increases. One could again speculate that the trend is caused by the reduction of $\mathrm{N}$ and thereby an increase of local $\mathrm{pH}$, but the results in buffered solution show the same, equally pronounced, trend (see below). Thus, it appears that the primary action of $\mathrm{N}$ is a reduction of the catalytic activity of the surface for the hydrogen reaction.

Experiments conducted with $1 \times 10^{-5} \mathrm{M}$ solution of Fe-ions allowed measurements of the reversible potential and the exchange current density, $i_{0}$, for Fe dissolution. Assuming that the activity of $\mathrm{Fe}$ on the oxide-free metallic surface is unity and independent of $\mathrm{N}$ content, the reversible potential, $\mathrm{E}_{\mathrm{o}}$ for $\mathrm{Fe} \rightarrow \mathrm{Fe}^{+2}$ reaction is $-1246 \mathrm{mV}$ MSE. Careful extrapolation of the partial anodic currents to this potential shows that the $i_{\mathrm{o}}$ increases with $\mathrm{N}$ in the film. The trend towards higher anodic activity with $\mathrm{N}$ has been reported by others (11), but the introduction of a fixed amount of Fe-ions (at a concentration which is higher than the yield of the corrosion reaction) allows quantitative evaluation of the dissolution rate. The rate varies from $8 \times 10^{-7}$ on Fe to $3 \times 10^{-6} \mathrm{~A} / \mathrm{cm}^{2}$ on Fe with $20.4 \mathrm{a} / \mathrm{o} \mathrm{N}$ (Table II). If the activity of the oxide-free surface is assumed to be less than unity, $\mathrm{E}_{\mathrm{o}}$ would systematically increase with an increase of $\mathrm{N}$ content, which would make the measured difference in $i_{\mathrm{o}}$ even larger. Thus the trend is correct and real.

Of the two $\mathrm{N}$ effects observed in deaerated sulfate solutions, namely an increase of $\mathrm{Fe}$ dissolution and a decrease of hydrogen evolution reaction, the latter is more pronounced and

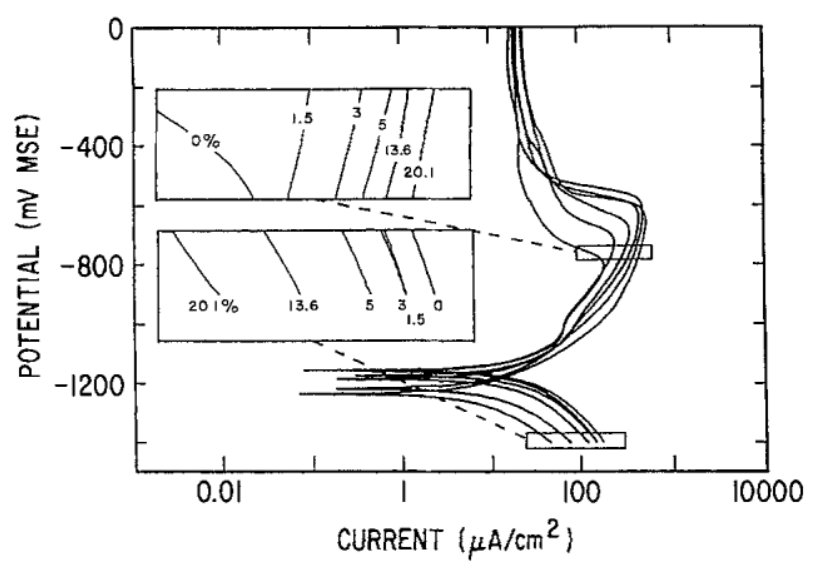

Fig. 4. Potentiodynamic polarization curves (with $5 \mathrm{mV} / \mathrm{s}$ ) on $\mathrm{Fe}-\mathrm{N}$ with $\mathrm{O}$ to 20.4 a/o $\mathrm{N}$ in boric acid/borate buffer, pH 7. 
Table II. $i_{0}$ for $\mathrm{Fe}$ dissolution reaction as a function of a/o $\mathrm{N}$, measured in sulfate, $\mathrm{pH} 7$, and boric acide/borate, pH 7.

\begin{tabular}{rrr}
\hline a/o N & $\begin{array}{r}i_{o}, \mathrm{~A} / \mathrm{cm}^{2} \\
\text { in sulfate }\end{array}$ & $\begin{array}{l}i_{o}, \mathrm{~A} / \mathrm{cm}^{2} \\
\text { in buffer }\end{array}$ \\
\hline 0 & $8 \times 10^{-7}$ & $5 \times 10^{-7}$ \\
1.5 & $8 \times 10^{-7}$ & $5 \times 10^{-7}$ \\
3 & $9.5 \times 10^{-7}$ & $2 \times 10^{-7}$ \\
5 & $1 \times 10^{-6}$ & $3 \times 10^{-7}$ \\
12 & $2.6 \times 10^{-6}$ & $4 \times 10^{-7}$ \\
20 & $3 \times 10^{-6}$ & $2 \times 10^{-7}$
\end{tabular}

produces the prevailing effect on the overall corrosion: with an increase of $\mathrm{N}$, the overall corrosion rate decreases as does the corrosion potential. Thus one can speculate that Fe-nitride crystallites in the Fe-matrix would have an effect of protecting the iron and not of enhancing the localized attack.

In all cases, except for pure Fe films, a large decrease in current caused by passivation was observed during potentiodynamic polarization. Thus, pure Fe films tend to dissolve and only for high $\mathrm{pH}$ solutions and fast sweep rates could we actually observe an active-passive transition. In the sulfate solution, the peak current decreases with an increase of a/o N, Fig. 3. Thus it would appear that either the kinetics of oxide formation are faster with an increase of $\mathrm{N}$ or that the oxide film which forms on Fe-N has a different composition and/or less difficulty in covering the small grain, smoother Fe-N surface.

The ellipsometric data obtained simultaneously with the potentiodynamic polarization curves in $\mathrm{pH} 7$ sulfate solution were greatly affected by Fe dissolution and surface roughening. These processes produced optical changes proportional to the magnitude of the peak current, but in all cases their effect is large enough to hide possible changes caused by the growth of the oxide. The experiments were thus repeated at higher $\mathrm{pH}$. The trend in potentiodynamic polarization curves in sulfate solutions with $\mathrm{pH}$ 7-10 remained similar to that given in Fig. 3 for $\mathrm{pH}$ 7. In $\mathrm{K}_{2} \mathrm{SO}_{4} / \mathrm{KOH}$ solution with $\mathrm{pH} 10$, the effect of roughening was small enough that the oxide growth could be followed by ellipsometry. The results, illustrated in Fig. 5, indicate that the oxide growth is practically identical for the films with $0.1 .5,3$, and $5 \%$ N. A slightly thicker oxide may form on Fe with 13 a/o $\mathrm{N}$ for which the biggest change in the oxide growth occurs at potentials between -0.96 and $-72 \mathrm{mV}$, i.e., well after the peak potential. The difference in thickness is only about $0.37 \mathrm{~nm}$ at $-0.72 \mathrm{~V}$. The data are identical in the current-potential region before the peak. Thus the difference in oxide growth kinetics is insignificant and provides no explanation for the observed decrease in the passivation current with the increase of $\mathrm{N}$ - content. 


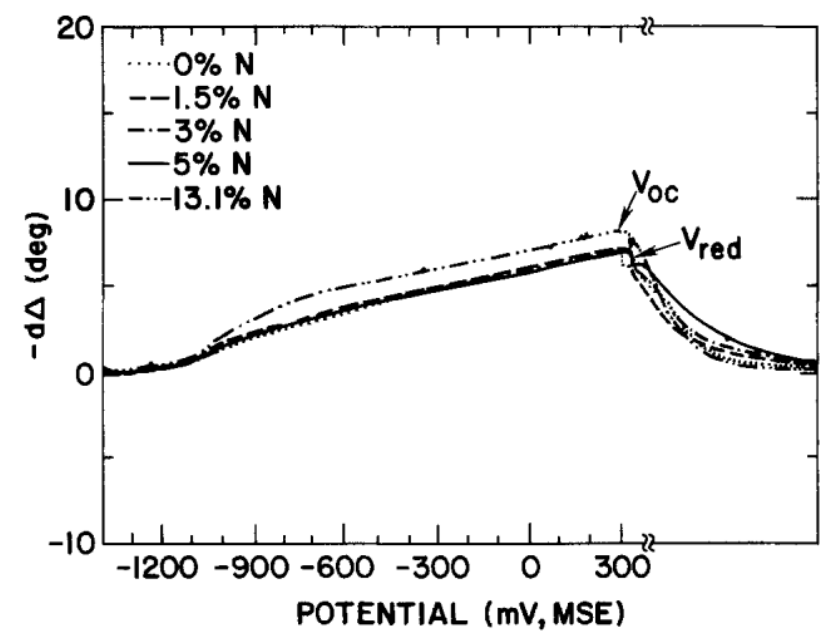

Fig. 5. Variation of $d \Delta$ or oxide growth with potentiodynamic scan in $\mathrm{pH} 10$, with a scan rate of $1 \mathrm{mV} / \mathrm{s}$. At the potential of $0.3 \mathrm{~V}$ the scan is discontinued and after a short time at the open-circuit potential (at which there is no change of $\Delta$ ) the film is reduced by an application of $-1.4 \mathrm{~V}$.

The mechanism of oxide growth on Fe $(16,17)$ might explain why the effect of nitrogen on oxide growth is small. The initial oxide formation proceeds by a two-dimensional growth of discrete centers, up to $30 \%$ coverage. At higher coverages the growth involves a rapid place-exchange step with the rate-determining discharge of $\mathrm{OH}^{-}$into sites where the metal is already attached to an $\mathrm{OH}$ group. The original $\mathrm{OH}$ group is displaced into the first layer of the metal atoms beneath the surface, forming a two-dimensional oxide lattice. As the rate-determining step involves not a surface $\mathrm{Fe}$, but a displaced $\mathrm{Fe}$, the effect of $\mathrm{N}$ is not noticeable.

The XPS spectra for anodic oxide films, formed by a 10 min potentiostatic oxidation at $0.1 \mathrm{~V}$, are similar to those for the native oxides, described above. The surface of Fe- $\mathrm{N}$ films again shows two $\mathrm{N}$ Is peaks, suggesting that there is a small but definite amount of oxidized $\mathrm{N}$ in the oxide film. Also, the oxide film on Fe-N with higher $\mathrm{N}$ content tends to be thicker than the oxide on Fe (as suggested by ellipsometry), but the difference is small.

As the kinetics of oxide growth offer no explanation for the effect of $\mathrm{N}$ on the active peak, the explanation could be provided by the presence of $\mathrm{N}$ in the oxide films on Fe-N. The prevailing $\mathrm{N}$ effect might, however, be connected with the spatial distribution of the newly formed oxide, which, for a similar thickness provides more effective coverage to the smoother, fine-grained Fe-N surface.

Effects of buffers on corrosion and passivation of $\mathrm{Fe}-\mathrm{N}$ films. - Boric acid/borate and phosphate solutions were used in our work primarily as buffers, to eliminate and illustrate the role of $\mathrm{pH}$ in possible cathodic reactions involving nitrogen. The buffers have shown, however, many other interesting effects. Comparison of Fig. 3 and 4 indicates that the rate of the hydrogen evolution reaction is much faster in the buffered than in the unbuffered electrolyte. The enhancement of the hydrogen evolution rate was observed equally for boric acid/borate as well as for phosphate buffers, Fig. 6. Such an effect of borate buffer has been reported previously (18), but to our knowledge this is the first report of a similar influence of phosphate.

The explanation for the effect of borate and phosphate that first comes to mind is that they simply buffer the surface $\mathrm{pH}$. During hydrogen evolution at applied cathodic potentials, the 
surface $\mathrm{pH}$ will tend to increase due to consumption of hydrogen ions. This increase in $\mathrm{pH}$ should lead to a decrease in hydrogen evolution rate for the unbuffered case. The buffers might simply prevent the $\mathrm{pH}$ increase, and thus result in a higher hydrogen evolution rate compared to the unbuffered case.

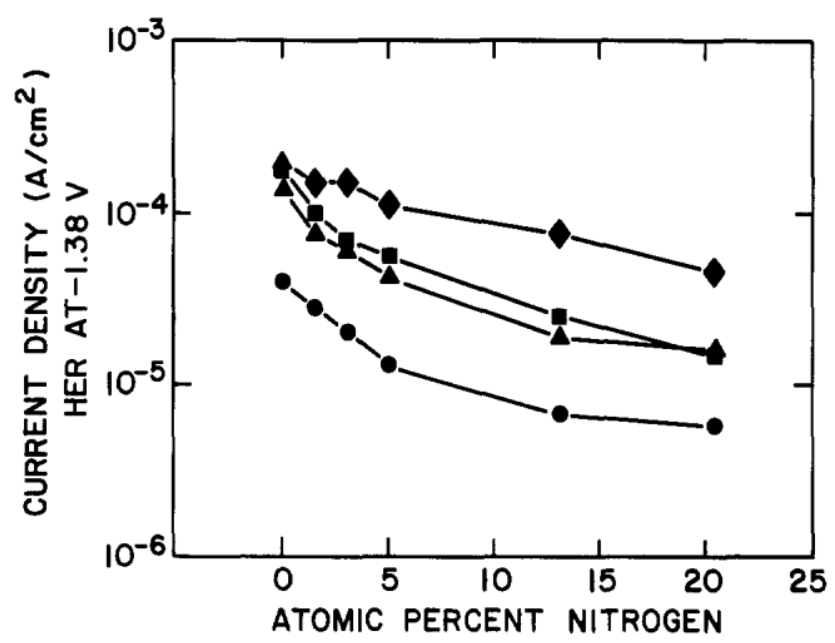

Fig. 6. The rate of hydrogen evolution reaction at $-1.38 \mathrm{~V}, \mathrm{MSE}$ in sulfate, $\mathrm{pH} 7$ (circle); boric acid/borate buffer, pH 7 (diamond); boric acid/borate buffer, pH 8.2 (triangle); and phosphate buffer, pH 8.2 (square).
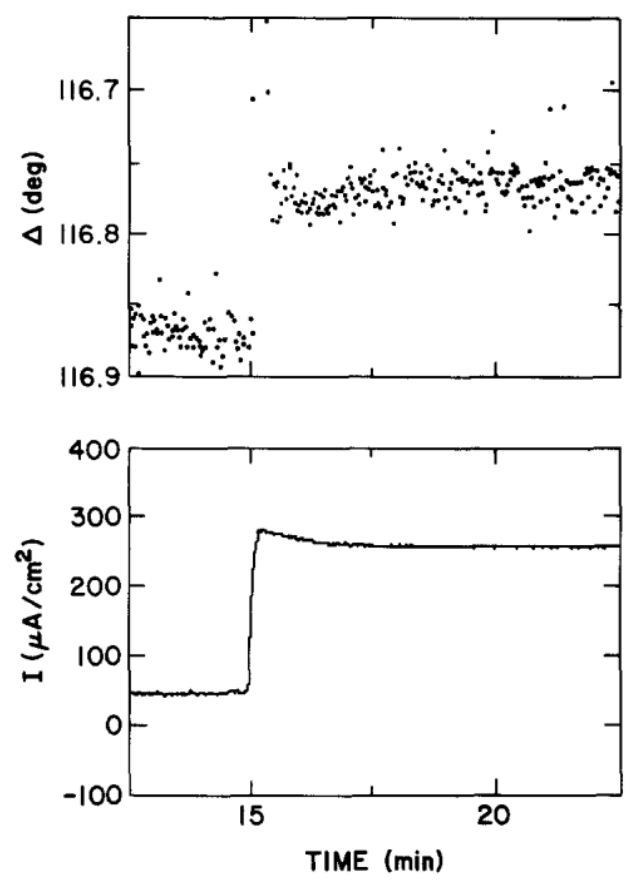

Fig. 7. Change of $A$ and cathodic current with an introduction of boric acid/borate buffer to Fe potentiostated at $-1.4 \mathrm{~V}$. 
There are, however, several indications that the role of these buffers might be different than a simple buffering action. The cathodic Tafel slope is $0.120 \mathrm{~V} / \mathrm{dec}$ even without the buffers so the hydrogen evolution reaction is under activation rather than diffusion control and a significant increase in $\mathrm{pH}$ should not occur. In Fig. 7 the current and $\Delta$ are plotted $v s$. time for the case of Fe at an applied cathodic potential. At $15 \mathrm{~min}, 10 \mathrm{ml}$ of $\mathrm{pH} 7$ borate buffer was injected into the cell which had previously contained $80 \mathrm{ml}$ of $0.1 N \mathrm{~K}_{2} \mathrm{SO}_{4}$. Prior to introduction of the borate, the current was constant with time, which is another indication that the surface $\mathrm{pH}$ was not changing. The cathodic current increased when the borate was added, in accordance with the curves in Fig. 3 and 4 . At the same time, $\Delta$ and $\psi$ also changed, indicating adsorption on the surface. The overall changes of $\Delta$ and $\psi$ were small, i.e., $-0.12^{\circ}$ and $+0.02^{\circ}$, respectively, which means that the average thickness of the adsorbed layer was less than $0.3 \mathrm{~nm}$. Both borate and phosphate have been reported to inhibit iron dissolution, participate in the passivation process, and facilitate the growth of passive film (19-21). As inhibitors they would be expected to adsorb (or react) with the electrode surface. Figure 7 indicates that borate does in fact adsorb onto a bare Fe surface. We have not yet measured the adsorption of phosphate, but one can assume that this too has to occur, and that both of these buffers act as surface-active species. Given the adsorbing nature of these buffers and the lack of evidence for a significant $\mathrm{pH}$ change in their absence, their effect on hydrogen evolution may result from the adsorption of new, hydrogen containing entities, such as $\mathrm{H}_{2} \mathrm{BO}_{3^{-}}, \mathrm{HPO}_{4}^{-2}$, or $\mathrm{H}_{2} \mathrm{PO}_{4^{-}}$, from which hydrogen discharge occurs easier than from $\mathrm{H}_{3} \mathrm{O}^{+}$ions.

The effect of $\mathrm{N}$ on the corrosion of Fe- $\mathrm{N}$ films in these buffers is similar to that in sulfate. The overall corrosion rate is determined by the rate of hydrogen evolution. As this rate is higher in the buffers, the corrosion rate and potential of each of the films are higher than in sulfate, but decrease with an increase of $\mathrm{N}$ content.

The $i_{\mathrm{o}}$ for Fe dissolution is lower in the buffer solution and independent of the $\mathrm{N}$ content (Table II). The adsorption of the buffer is apparently stronger on Fe than on FeN. This is visible from the pronounced effect the buffer has on the ability of Fe to passivate, which decreases as $\mathrm{N}$ increases. In the buffered electrolytes, the peak current decreases with a decrease in a/o N, Fig. 4, which is just the opposite of that observed in sulfate solutions. This is very noticeable in $\mathrm{pH} 7$ (as illustrated in Fig. 4) but much less in higher pH's where all samples passivate more readily. 


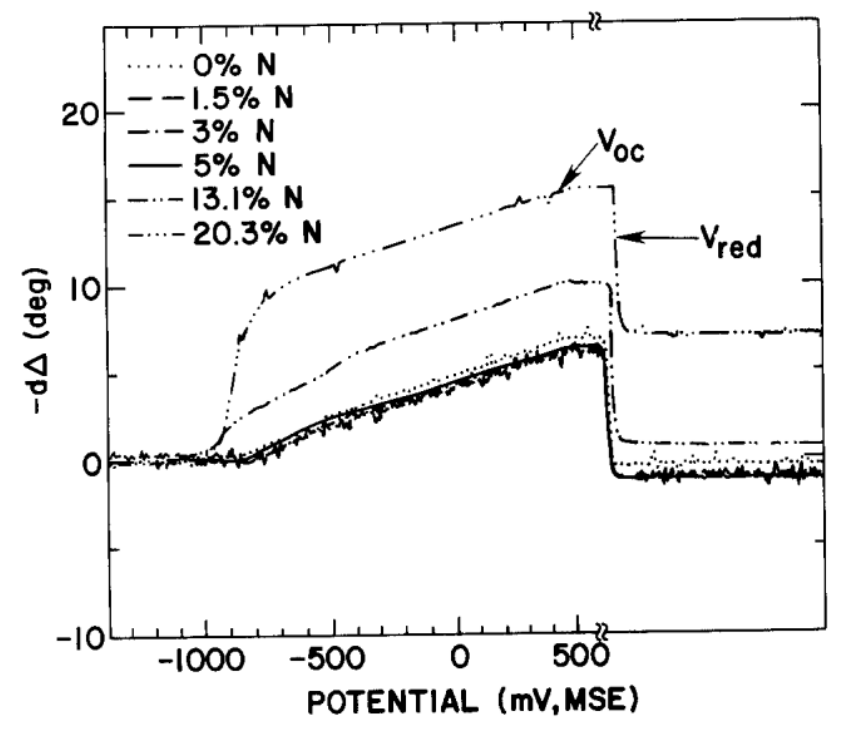

Fig. 8. Oxide growth $(d \Delta)$ in boric acid/borate buffer, $\mathrm{pH} 7$ during potentiodynamic oxidation, with a scan rate of $5 \mathrm{mV} / \mathrm{s}$. At the potential of $0.3 \mathrm{~V}$ the scan is discontinued, and after a short time at the open-circuit potential (at which there is no change of $A$ ) the film is reduced by an application of $-1.4 \mathrm{~V}$.

Ellipsometric data corresponding to oxide growth on $\mathrm{Fe}$ and $\mathrm{FeN}$ films during potentiodynamic polarization in boric acid/borate buffer, $\mathrm{pH} \mathrm{7,} \mathrm{are} \mathrm{given} \mathrm{in} \mathrm{Fig.} \mathrm{8.} \mathrm{Oxide} \mathrm{growth}$ on a pure Fe film seems to be practically identical to that reported for a bulk Fe sample in boric acid/borate buffer, $\mathrm{pH} 8.4(16,17)$. The film thickness at $-0.3 \mathrm{~V}$ is about $2.5 \mathrm{~nm}$ which is similar to that formed in sulfate solution, $\mathrm{pH} 10$. The increase of $\mathrm{A}$ with $\mathrm{N}$ in the active-potential region represents either a thicker film or surface roughening. The films with $20.4 \%$ and $13.1 \% \mathrm{~N}$ are unquestionable roughened, since $\Delta$ does not recover to its original value upon reduction of the anodic film. The irreversible change upon reduction reflects a permanent change of the surface. In this case, roughening is the only plausible explanation. Films with less $\mathrm{N}$ seem to have the same or larger change in $\Delta$ due to oxide reduction compared to that measured during oxidation. This can be explained by formation of an Fe-rich surface after reduction. During anodic polarization scans, the potential at which A first changes is lower for higher N contents, which indeed indicates that these films roughen in the initial stage of Fe dissolution and oxidation. Because of the effects of roughening on $\Delta$ and $\psi$, it is difficult to judge if the overall oxide thickness increases with the $\mathrm{N}$ content. However, it is very clear that in borate solutions the initial oxide film on pure Fe prevents roughening and causes a significant decrease of the anodic current by acting as a protective and effective barrier for Fe-dissolution. Furthermore, this effectiveness decreases with increasing $\mathrm{N}$.

$\mathrm{Fe}-\mathrm{N}$ in aerated electrolytes.-In the presence of oxygen in the selected $\mathrm{pH}$ range from 7 to 10 , all films spontaneously passivate (Fig. 9), with a significant increase of the corrosion potential and a reduction of the corrosion rate. The prevailing cathodic reaction is oxygen reduction, which is diffusion limited and not a function of the $\mathrm{N}$ content. Thus the corrosion rate follows the variation of the Fe-dissolution reaction and increases with increasing $\mathrm{N}$ content.

The results offer an explanation for the fast dissolution of $\mathrm{N}$ rich films in the air-exposed acidic solutions after dissolution of the native oxide, as described above. Without an oxide, $\mathrm{Fe}$ 
dissolution proceeds at low corrosion potentials, with the kinetics characterized by a low anodic Tafel slope of $0.06 \mathrm{~V} /$ decade or less, and is accompanied by both a fast, diffusion-limited oxygen reduction and a relatively slow, activation-controlled hydrogen reaction. The overall corrosion is then determined primarily by the oxygen reduction and the substrate-dependent Fe dissolution which increases with $\mathrm{N}$.

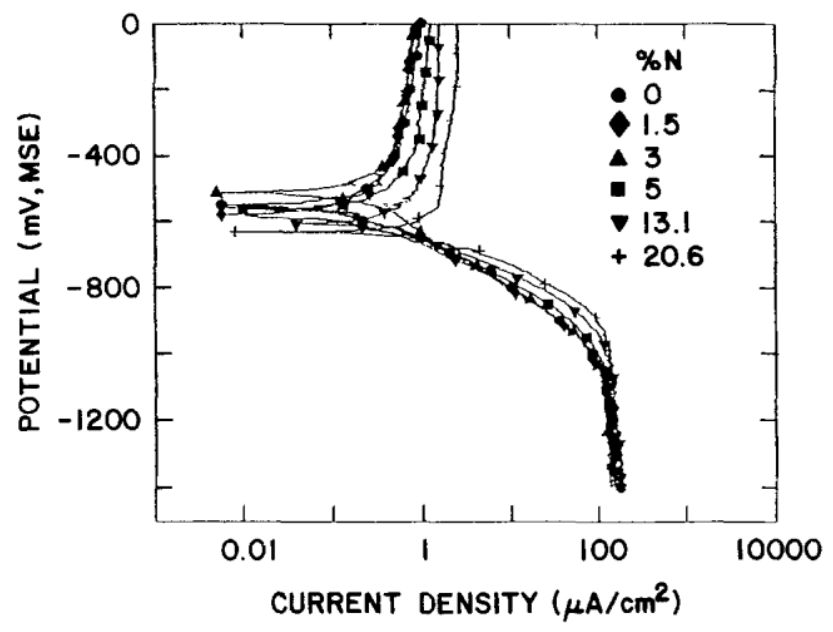

Fig. 9. Potentiodynamic polarization curves measured on reduced Fe-N films in aerated sulfate solution, pH 7 , with a scan rate of $1 \mathrm{mV} / \mathrm{s}$.

\section{Summary}

Corrosion and passivation behavior of $\mathrm{Fe}$ and $\mathrm{Fe}-\mathrm{N}$ films were studied by electrochemical techniques combined with in situ applied ellipsometry and ex situ TEM and XPS analyses. The following conclusions can be drawn.

1. The stability of the native oxide on Fe-N films increases with $\mathrm{N}$ content. The oxide is basically $\mathrm{Fe}_{2} \mathrm{O}_{3}$, but contains a small amount of oxidized nitrogen. The increased stability of the oxidized surface might be due to combined effects of the $\mathrm{N}$ in the oxide, increased oxide thickness, and reduction in grain size.

2. Nitrogen in the film reduces the catalytic activity of the oxide-free surface for the hydrogen evolution reaction, does not affect the kinetics of oxygen reduction, and increases the rate of Fe dissolution. Thus, in deaerated solutions the corrosion rate of oxide-free surface decreases with increasing $\mathrm{N}$, while it increases in aerated solutions.

3. Borate and phosphate buffers increase the catalytic activity for hydrogen evolution of all films, and thereby increase the corrosion rate in deaerated solutions.

4. Despite the increased protection of native oxides on Fe-N films compared to pure $\mathrm{Fe}$, the corrosion rate of oxide-free Fe-N surface (i.e., reduced or mechanically abraded as in head fabrication process) is faster than that of $\mathrm{Fe}$.

\section{Acknowledgments}


Authors are indebted to J. W. Lee for the TEM analysis, J. Coleman for RBS results and J. Horkans for stimulating discussions. Special thanks are due to M. E. Re and B. C. Webb, whose interest and curiosity prompted this work.

Manuscript submitted Nov. 21, 1991; revised manuscript received Feb. 24, 1992. This was Paper 404 presented at the Phoenix, AZ, Meeting of the Society, Oct. 13-17, 1991.

IBM T. J. Watson Research Center assisted in meeting the publication costs of this article.

\section{REFERENCES}

1. J. Eckenrod and C. W. Kovack, ASTM STP 679, p. 17, ASTM, Philadelphia, PA (1977).

2. A. J. Sedriks, Intl. Met. Rev., 28, 306 (1983).

3. M. Naoe, M. Yamaga, and N. Terada, IEEE Trans. Magnetics, MAG-21,1900 (1985).

4. J. Lo, L. Franco, T. C. Huang, T. W. Wu, D. Miller, and R. Campbell, ibid., MAG-24, 3081 (1988).

5. Y. Nagai, A. Tago, K. Yanagisawa, and T. Toshima, J. Appl. Phys., 61, 3841 (1987).

6. M. Janik-Czachor, E. Lunarska, and S. Smialowska, Corrosion, 31, 394 (1975).

7. K. Osozawa and N. Okato, "Passivity and Its Breakdown on Iron and Iron-Based Alloys," p. 135, USA-Japan Seminar, Honolulu, HI, NACE Houston, TX (1976).

8. Y. C. Lu, R. Bandy, C. R. Clayton, and R.C. Newman, This Journal, 130, 1774 (1983).

9. R. C. Newman and T. Shahrabi, Corros. Sci., 27, 827 (1987).

10. S. D. Chyou and H. C. Shin, Corrosion, 47, 31 (1990).

11. R. D. Willenbruch, C. R, Clayton, M. Oversluizen, D. Kim, and Y. Lu, in "Proceedings of 6th International Symposium on Passivity," Sapporo, Hokkaido, Japan, Sept. 24-28, 1989.

12. V. Brusic, M. Russak, R. Schad, G. Frankel, A. Selius, D. Dimilia, and D. Edmonson, This Journal, 136, 42 (1989).

13. M. A. Russak, C. V. Jahnes, E. Klokholm, J. W. Lee, M. E. Re, and B. C. Webb, Paper presented at 5th Joint MMM-Intermag. Conference (MG-06), Pittsburgh, PA, June 1991.

14. W. M. Riggs and M. J. Parker, in "Methods of Surface Analysis," A. W. Czanderna, Editor, Elsevier Sci. Pub., New York (1975).

15. CD. Wagner, W. M. Riggs, L. E. David, and J. F. Moulder, "Handbook of X-RayPhotoelectron Spectroscopy," G. E. Muilenberg, Editor, Perkin-Elmer Corp., Eden Prairie, MN (1979).

16. V. Brusic, PhD Thesis, University of Pennsylvania, Philadelphia, PA (1971).

17. J. O'M. Bockris, W.A. Genshaw, V. Brusic, and H. Wroblowa, Paper presented at the Faraday Society Meeting, London, Dec. 1970.

18. J. Horkans, This Journal, 126, 1861 (1979).

19. K. Ogura and K. Sato in "Passivity of Metals," R. .P. Frankenthal and J. Kruger, Editors, p. 463, Corrosion Monograph Series, The Electrochemical Society, Princeton, NJ (1978).

20. K. Ogura, J. Electroanal. Chem., 79, 149 (1977).

21. B. MacDougall and J. A. Bardwell, This Journal, 135, 2437 (1988). 